УДК 531.768

DOI: http://doi.org/10.20535/0203-3771372019177769

O. Ivanova ${ }^{1}$, senior lecturer, D. Ilchishyna ${ }^{2}, P h D$, P. Palamarchyk ${ }^{3}$, student

\title{
ON THE THEORY OF THE ELASTIC BODIES COLLISIONS
}

Ua У роботі досліджується динамічна контактна задача. Зокрема, розглядаються два способи визначення коефіцієнта відновлення, що є інтегральною енергетичною характеристикою процесу удару.

Показано, що значення цього коефіцієнта, яке одержано за наявності впливу поверхневих хвиль Релея ближче до його значення, отриманого експериментальним шляхом.

Ru В работе проводится исследование динамической контактной задачи. В частности, рассматриваются два способа определения коэффициента восстановления, который является интегральной энергетической характеристикой процесса удара.

Показано, что значение этого коэффициента, полученное при наличии влияния поверхностных волн Релея ближе к его значению, полученному экспериментальным путем.

\section{Introduction}

About 100 years ago G. Hertz advanced the theory of contact static interaction of elastic bodies and the collisions theory of such bodies as a secondary result of the research in electrodynamics.

Experiments and theoretical studies within the elasticity theory do not confirm the idea of I. Newton that the recovery coefficient in the elastic bodies collision is equal to one. This is evident from the data included, as a rule, in all textbooks on theoretical mechanics.

Both theories are among the most pressing problems of modern mechanics. The evaluation criterion for those or other theoretical results is considered to be, in particular, the recovery coefficient $\varepsilon$ which is an integral energy characteristic of the impact process.

\section{Problem}

The purpose of this paper is to supplement the results obtained by the authors in the paper [2].

The theory of collisions of G. Hertz [1] is, in essence, a theory of the motion of a material point which is under the action of a nonlinear restoring

\footnotetext{
${ }^{1}$ Igor Sikorsky Kyiv Polytechnic Institute

${ }^{2}$ Igor Sikorsky Kyiv Polytechnic Institute

${ }^{3}$ Igor Sikorsky Kyiv Polytechnic Institute
} 
$\overline{\text { force } P \text {. This dependence (nonlinearity) should be attributed to weak nonlinear- }}$ ities, since the law of motion of a point and the quantities associated with it can be approximated with sufficient accuracy by simple harmonic oscillation:

$$
x=\frac{v_{o}}{n} \sin n t, \quad n=\frac{\pi}{\tau^{*}} \cdot \frac{v_{o}^{\frac{1}{5}}}{m^{\frac{2}{5}} k^{\frac{3}{5}}}, \quad \tau^{*}=3,2 .
$$

Therefore

$$
P=-c x=-m v_{o} n \sin n t .
$$

This circumstance is implicitly reflected in [2]. It applies a superposition of the restoring force and the forces inverse in the direction of the force of inertia. In addition to [2], we present two more elementary methods for estimating the recovery coefficient for elastic bodies collisions.

\section{Two ways to determine the recovery coefficient}

1. The system of colliding bodies is replaced by a body of mass $m=\frac{m_{1} m_{2}}{m_{1}+m_{2}}$ striking against a plate supported by a spring with a nonlinear relationship between the longitudinal displacement of the plate and the force of interaction $P_{G}$ between the body and the plate. Mass of the plate and the spring will lead to the point of initial contact between the body and the plate and denote $m_{o}$ this mass is included in the movement at a time $t=0$ and is a source of fictitious force acting on the plate and the spring, which was considered in [2]. This force reduces the force of interaction between the body and the elastic elements at $v_{k}>0$.

Its impulse

$$
\int_{0}^{t} \vec{F} d t=m_{o} \vec{v}_{k}-m_{o} \vec{v}_{o}
$$

Since for particles of an impacted body, the initial velocity is zero and the added mass $m_{o}$ moves with the body at the velocity of the body, then

$$
\int_{0}^{t} \vec{F} d t=m_{o} \vec{v}_{k} .
$$

Applying the impulse theorem to the body being struck, we find:

$$
m v_{k}-m v_{o}=m_{o} v_{k} \sigma(t)-\int_{0}^{t} P_{G} d t
$$

This equality contains projections of vector $\mathrm{s} \vec{v}_{k}, \vec{v}_{o}$ and $\vec{P}_{G}$ on the axis $o x$ directed along the axis of the spring towards the initial movement of the 
body being struck. Here $\sigma(t)$ is the Heaviside function. The first term on the right-hand side describes the decrease in the interaction force with $v_{k}>0$.

Let the moment the end of the strike be $t^{*}$. Then [3]:

$$
\int_{0}^{t} P_{G} d t=2 m v_{o}
$$

and from (5) we get:

$$
v_{k}\left(t^{*}\right)=-\frac{m}{m-m_{o}} v_{o}, \quad \varepsilon_{k}\left(t^{*}\right)=\frac{m}{m-m_{o}} .
$$

Increase of $m_{o}$ leads to increase of $\varepsilon_{k}$.

On the basis of [1] and [2] we get:

$$
\frac{m}{m-m_{o}} \cong 1,32, \quad m_{o} \cong 0,244 m .
$$

Thus, the result following from the content of the book [1] allows to find the reduced mass $m_{o}$ of the elastic elements of the system. Now we can consider the motion of the striking body, including the influence of the inertial forces of the elastic elements. We have:

$$
m v-m v_{o}=\int_{0}^{t} P_{x} d t-m_{o} v_{\sigma}(t) .
$$

Here $P$ is the force of contact interaction between bodies. This force is unknown. If we put

$$
P_{x} \cong P_{G x}=-P_{G},
$$

then

$$
v\left(t^{*}\right)=-\frac{m}{m+m_{o}} v_{o}
$$

accordingly

$$
\varepsilon\left(t^{*}\right)=\frac{m}{m+m_{o}}=\frac{1}{1,244} \cong 0,82 .
$$

2. The above assumption concerning force $P$ is essential. Let us show that the combination of the elementary theory presented here and the content [2] lead to a significantly lower value of the recovery coefficient.

It follows from (5) and (9)

$$
m \frac{d v_{k}}{d t}=-P_{G}+P_{(i)}, \quad m \frac{d v_{G}}{d t}=-P_{G},
$$

where

$$
P_{(i)}=\frac{d}{d t} m_{o} v_{k}
$$


This is taken into account when determining the sign of $P_{(i)}$, that there are considered the forces acting on the striking body, and not on the elastic elements. Based on (13) and [2]:

$$
P_{(i)}=m\left(\frac{d v_{k}}{d t}-\frac{d v_{G}}{d t}\right) .
$$

We find approximately true force of the interaction:

$$
P=P_{G}+P_{(i)}=m\left(\frac{d v_{k}}{d t}-2 \frac{d v_{G}}{d t}\right) .
$$

Substituting (15) into (8) and taking into account that

$$
v_{K_{o}}=v_{G_{o}}=v_{o}
$$

we get

$$
\left(m+m_{o}\right) v=-m\left(v_{K}-2 v_{G}\right) \text {. }
$$

Hence:

$$
\left(m+m_{o}\right) v\left(t^{*}\right)=-m\left[v_{K}\left(t^{*}\right)-2 v_{G}\left(t^{*}\right)\right] .
$$

Or on the basis of (6) - (7):

$$
\left(m+m_{o}\right) v=-m\left[2-\frac{m}{m-m_{o}}\right] v_{o}=-0,68 m v_{o} .
$$

Accordingly, on the basis of (12)

$$
v=-0,68 \frac{m}{m+m_{o}} v_{o} ; \quad \varepsilon\left(t^{*}\right) \cong 0,556 .
$$

This is the lowest value of the recovery coefficient from those found by us.

\section{Conclusions}

Apparently, the value specified in [2] should be preferred, since it has been obtained with the least amount of additional assumptions.

The lowest value of the recovery coefficient $\varepsilon$ is close to the recovery coefficient for steel given in the textbooks of theoretical mechanics and monographs on the theory of impact [4], [5].

\section{Reference}

1. Kilchevsky N. A. Dynamic contact compression of solids. Strike K., "Naukova Dumka", 1976.

2. Ivanova O. N., Ilchishyna D. I. On the influence of surface-wave-induced strike on the recovery factor., ISMC No. 15, 2016. 
$\overline{\text { 3. Ivanova O.N., Ilchishyna D. I., Approximate methods for estimating the }}$ recovery coefficient for elastic bodies., MGS, No. 29, 2015.

4. V. Goldsmith, Strike., M., ILS, 1965.

5. VL Mac-Millan. Dynamics of a solid body, M., IL, 1951. 